\title{
Cadê o parque que deveria estar aqui? As trajetórias de uma prática de ensino em Teatro na comunidade do Abraão
}

\section{Dónde está el parque que debería estar acá? Las trayetorias de una práctica de enseñanza del teatro en la comunidad de Abraão}

\author{
Itamar Wagner Schiavo Simões \\ Mestre em Teatro pela Universidade Estadual de Santa Catarina (UDESC) - itaschiavo@gmail.com - \\ http://orcid.org/0000-0001-8360-3509
}

\begin{abstract}
Resumo
Apresenta uma tessitura das trajetórias de uma prática de estágio de Teatro em Comunidades, na qual foi proposto um trabalho de intervenção urbana por meio da linguagem teatral. O processo de ensino-aprendizagem da linguagem teatral é apresentado e analisado, assim como os procedimentos metodológicos utilizados para a construção da performance, elaborada por atores da comunidade a partir do cruzamento de suas próprias narrativas com as de outros moradores sobre a situação enfocada: os caminhos entre o projeto e a construção do Parque do Abraão. O aporte teórico deste artigo é constituído por autores da área da pedagogia teatral (Spolin, 2001), (Cabral, 2012), (Desgranges, 2006); da performance (Muniz, 2011), (Oliveira, 2013) e da arquitetura e urbanismo (Pereira, 2015). Os principais conceitos e temas abordados são relativos à questão da ressignificação do espaço público por meio da atividade artística; intervenção urbana; associação entre cerimônia teatral e rito social; urbanidade enquanto processo de apropriação e lugar praticado.
\end{abstract}

Palavras-chave: Intervenção urbana. Performance. Ensino do teatro. Teatro em comunidades.

\begin{abstract}
Resumen
Presenta una tesitura de las trayectorias de una práctica de teatro de Teatro en Comunidad, en el cual se ha propuesto un trabajo de intervención urbana a través del lenguaje teatral. El proceso de enseñanza-aprendizaje del lenguaje teatral se presenta y analiza, así como los procedimientos metodológicos utilizados para la construcción de performance por actores de la comunidad a partir del entrecruzamiento de sus propias narrativas con las de sus vecinos sobre la situación enfocada: los caminos entre el proyecto y la construcción del Parque de Abraão. El aporte teórico de este artículo está constituido por autores del área de la pedagogía teatral (Spolin, 2001), (Cabral 2012), (Desgranges, 2006); de la performance (Muniz, 2011), (Oliveira, 2013) y de la arquitectura y urbanismo (Pereira, 2015). Los principales conceptos y temas abordados son referentes a la cuestión de la resignificación del espacio público a través de la actividad artística; intervención urbana; asociación entre ceremonia teatral y rito social; urbanidad como proceso de apropriación y lugar practicado.
\end{abstract}

Keywords: Intervención urbana. Performance. Ensino del teatro. Teatro en comunidad.
Recebido em: 29/05/2018

Aceito em: 02/02/2019 


\section{O PONTO DE PARTIDA}

A prática descrita nesse artigo se refere a atividade de estágio da disciplina Teatro em Comunidades II do Curso de Bacharelado e Licenciatura em Teatro da UDESC, realizada no segundo semestre de 2016. Sua realização partiu da iniciativa de um grupo de moradores interessados em desenvolver um projeto de arte para a comunidade. Moradores, que, por ironia, vizinhos, só cheguei a conhecer através do interesse em trabalhar com teatro. Esse grupo de pessoas, além do interesse em desenvolver um projeto artístico para a comunidade do Abraão, possuía uma proposta de trabalho de discutir e abordar, por meio de uma atividade teatral, questões emergentes no cotidiano da comunidade, tais como: especulação imobiliária, poluição da praia, ausência de um parque, para o qual, inclusive, já existe um projeto, porém ainda não saiu do papel.

Saltou aos meus olhos, no primeiro contato com o grupo, sua vontade de habitar distintos espaços da comunidade, uma consciência de cidadania e de cuidado com o espaço público que precisava ser transmitida para outros moradores. Percebi atribuição de significados, por eles, a distintos espaços da comunidade, e necessidade de ressignificação destes espaços para si mesmos e para outras pessoas do bairro. Essas percepções direcionaram o meu olhar para o planejamento de um processo de trabalho o qual não poderia ser compartilhado com a comunidade em outro espaço que não fosse o espaço público, buscando sensibilizar o olhar dos moradores para as condições destes locais.

Assim, foi traçada uma proposta de trabalho com intervenção urbana. Esta proposta dialoga com o interesse do grupo que demandou este trabalho de estágio, de empreender um movimento cultural na localidade, inicialmente, por meio da criação de um grupo de teatro comunitário. Acredito que o trabalho de intervir no espaço público contribui para a própria divulgação do grupo junto à comunidade, favorecendo a vinda de novos participantes. Pensando na perspectiva do interesse do grupo, esse trabalho poderia frutificar e gerar outros processos de revitalização artística de espaços da comunidade, assim como contribuir para que outras performances sejam criadas, as quais possam abarcar outras questões que o grupo deseja dialogar com a comunidade.

O conceito de intervenção urbana é bastante amplo e engloba manifestações de distintos campos artísticos no espaço da rua, seja da performance, do teatro, das artes visuais etc., tendo em comum uma proposta de promover um novo modo de apreciação do espaço urbano: "[são] ações 
que interferem em algo pré-existente, redefinindo funcionalidades, formas de uso, de ocupação e instaurando transformações ou reações no plano físico, intelectual e sensorial" (OLIVEIRA, 2013, p. 36).

No ponto de partida percebi que intervenções por meio da atividade teatral teriam o potencial de promover a criação de narrativas sobre e em determinados espaços da comunidade, gerando novas percepções e configurações destes espaços, mediante a discussão de problemas diretamente ligados à qualidade de vida dos moradores, contribuindo para o envolvimento das pessoas com os problemas do lugar, trazendo sensação de pertencimento.

Uma proposta artística no espaço público se caracteriza como algo extra cotidiano no qual ocorrem múltiplas referências que constituem diferentes códigos culturais, experiências e linguagens, tanto por parte de quem faz, como por parte de quem vê. Para Cabral (2012, p. 19-20):

a identificação individual e pessoal com o lugar pode ser vivenciada através de uma experiência estética que parta da associação entre a cerimônia teatral e a cerimônia social, que tem em comum a identificação e a delimitação de um espaço de solenidade, a presença de atores ou indivíduos que se dão a ver e a linguagem poética (extra cotidiana).

Esta ideia de associação entre cerimônia teatral e cerimônia social me parece adequada para elucidar a importância da proposta de compartilhar o trabalho a ser desenvolvido no espaço urbano, loco das inquietações do grupo que solicitou o trabalho teatral. Desta forma, no ponto de partida foi traçado, não os caminhos a serem percorridos, mas o ponto de chegada: o compartilhamento da experiência com os demais moradores, in loco, no lugar específico que enseja a discussão artística.

\section{A PRIMEIRA ETAPA DA CAMINHADA}

$\mathrm{Na}$ primeira parte da caminhada surgiram algumas facilidades devido ao interesse do grupo que desejava desenvolver o trabalho, o qual não mediu esforços para divulgar os encontros com a comunidade e providenciar o local para os encontros. A primeira reunião foi no salão paroquial da igreja, no qual foi realizada uma conversa sobre questões específicas da comunidade, em que os moradores tiveram a oportunidade de lançar seus olhares para o cotidiano do lugar, avaliando as facilidades e as dificuldades de habitar aquela localidade. A questão da especulação imobiliária, do crescimento desordenado e desorganizado rendeu bastante discussão, assim como o abandono de alguns espaços da comunidade pelo poder público. A ausência do parque, para o qual 
já existe um projeto que representa um grande anseio da comunidade, foi introduzida e relacionada com o problema da especulação imobiliária e o abandono de alguns espaços.

Propus neste encontro, como forma de se conhecer e se integrar, o jogo das trajetórias em que a sala se transforma em um grande mapa imaginário e cada jogador realiza sua trajetória desde que nasceu e como chegou até aquela localidade, pontuando as especificidades dos caminhos percorridos e as fases marcantes de sua vida.

Nesta primeira reunião, foi definido outro local para os encontros do grupo, o espaço de uma ONG que desenvolve o Projeto Família Feliz, a qual oferece atividades educativas e culturais para as crianças no horário em que elas não estão na escola. Trata-se de um espaço bastante apropriado para a atividade teatral, sala ampla e arejada com cadeiras, ventiladores, banheiro e água. Os encontros seriam todas as quintas das $19 \mathrm{~h} 30$ às $21 \mathrm{~h} 30$.

\section{UM DESVIO}

Um dos problemas enfrentados na caminhada se configurou na primeira parte do percurso. O grupo de trabalho começou a ter uma maior frequência de crianças do que de adultos e esta adversidade colocou em cheque o projeto da prática de ensino. Com um grupo majoritário de crianças, a proposta com intervenção urbana seria enormemente dificultada e até mesmo inadequada. Em primeiro lugar, esta proposta se configura como uma ação que possui uma reverberação política com a qual as crianças não poderiam contribuir tanto quanto os adultos. Ademais, com um grupo de crianças o caráter horizontal de criação pretendido na elaboração do trabalho teatral, teria que seguir por vias de percurso mais longas, modificando todo o planejamento. Ainda, entendi que um desvio dos interesses do grupo que demandou esta prática de ensino, poderia causar desânimo e desistência dos adultos, comprometendo o desenvolvimento de um trabalho comunitário com potencial de prosperar.

Adotamos uma estratégia de fazer mais uma divulgação dos encontros do grupo na comunidade. Panfletos foram espalhados por diversos pontos do comércio, residências e condomínios. O trabalho surtiu efeito e recebemos novos interessados no projeto. No entanto, as crianças interessadas não foram dispensadas e foi configurado um grupo de trabalho misto com predomínio de adultos. 


\section{TRAJETÓRIAS DA CAMINHADA}

Com grupo e local definidos para os encontros começamos a delinear as trajetórias desta caminhada. A grande maioria dos integrantes do grupo nunca tinham tido contato anterior com atividades teatrais, sendo necessário um processo de iniciação na linguagem teatral. Para tanto, criei uma proposta de trabalho inspirada no estudo de Spolin (2001) e seu sistema de jogos teatrais.

O trabalho que Spolin (2011) propõe está ancorado na ideia de que a capacidade de atuação pode ser desenvolvida por todas as pessoas, desde que elas estejam disponíveis para experienciar. Buscamos desenvolver nos participantes, nestes primeiros encontros, os princípios básicos para se colocar neste lugar: estar atento ao ambiente e ao espaço; ampliar o olhar; observar com atenção o que os colegas fazem e propõem; sentir o ambiente e o espaço que os circunda; observar as sensações que se inscrevem no corpo e desenvolver a habilidade de prontidão.

O trabalho com o jogo teatral traz a possibilidade de exploração dos níveis intelectual, físico e intuitivo dos participantes do grupo. Desgranges (2006, p. 111), em suas considerações sobre o jogo teatral a partir da obra de Spolin, argumenta que os participantes são desafiados, a cada jogo de regras, a elaborar respostas próprias na resolução dos problemas de atuação propostos. Esses problemas se tornam mais complexos na medida em que o grupo avança na experimentação e compreensão das propostas. Os jogos permitem que o grupo investigue características dos diversos aspectos de uma encenação, experimentando diferentes elementos da linguagem do teatro, tais como a percepção espacial e cenográfica (ONDE), a construção de personagens (QUEM) e o desenvolvimento da ação dramática (O QUÊ). Além da experimentação da cena, os participantes elaboram análises críticas do que foi realizado.

No trajeto até os locais de interesse do grupo e do projeto, ou seja, os espaços públicos que seriam problematizados em cena; os aspectos da encenação, tal como propostos por Spolin, foram trabalhados em estreita ligação com a comunidade e os interesses artísticos do grupo. Inicialmente deixei livre a escolha tanto do onde, do quem e do quê (com a premissa de que deveriam estar relacionados com a comunidade), para em seguida voltar a explorar estes aspectos aumentando o grau de complexidade das regras e restringindo-os ao parque e à praia.

O elo de ligação criado com o espaço definido foi de grande valia, pois alguns personagens e situações dramáticas que estiveram conosco neste momento da caminhada, retornaram em outro ponto do trajeto, quando desenvolvemos o processo de criação das cenas da intervenção. Desta 
maneira, o trabalho com o quem, o onde e o quê foi fundamental para o grupo dar seus primeiros passos no processo de apreensão das peculiaridades da linguagem teatral, e, ao mesmo tempo, para introduzir temáticas da intervenção criadas em seguida. Esse processo foi importante para o aprendizado dos integrantes do grupo, no sentido de perceberem que podem ser tecidas relações entre todas as atividades propostas, jogos e dinâmicas com a criação da cena.

Ao avaliar este processo de trabalho em relação às especificidades do projeto de estágio, entendi que não teríamos tempo hábil para desenvolver uma abordagem cênica dos espaços parque e praia. Optamos pelo primeiro, deixando a questão da praia poluída para outra trajetória a ser percorrida pelo grupo.

\section{A SEGUNDA ETAPA DA CAMINHADA}

Chegou o momento no qual o grupo tomou a direção mais próxima do ponto de chegada. Nessa parte da caminhada, o objetivo foi a criação da performance de intervenção urbana a ser realizada no espaço destinado à construção do parque. O parque ainda não está lá, nem o início das obras, por diversas razões que inquietam os moradores. Eles elaboraram muitas narrativas sobre a situação e este foi o ponto sobre o qual eu e o grupo nos debruçamos na busca de elementos cênicos para construir nosso trabalho.

O projeto desta prática de ensino está ancorado em um conceito de urbanidade que pressupõe a mistura de elementos arquitetônicos, naturais e humanos na paisagem e na vida urbana (PEREIRA, 2015). Assim, importa a diversidade no processo de apropriação da cidade, relacionado aos modos de uso do espaço público. De acordo com Pereira (2015), urbanidade é, por um lado, um conjunto de características e qualidades, e, por outro, presença e apropriação das pessoas. Nossa proposta de intervenção caminhou na direção de se apropriar de parte do espaço vazio e inóspito onde seria construído o parque, buscando torná-lo atrativo tal como o parque seria se estivesse lá, e ao mesmo tempo, chamando a atenção para a situação indefinida do parque, desejo dos moradores da comunidade.

Os modos de apropriação do espaço público têm a ver com a tensão entre os termos espaço e lugar. Os espaços definem-se como lugares por meio da singularidade da experiência humana no ambiente físico. Eles possuem, simultaneamente, uma capacidade simbólica e uma 
identidade própria sendo configurados a partir de uma combinação de espaço construído e espaço vivido (PEREIRA, 2015).

Esse trabalho busca instaurar, através da intervenção teatral, no espaço destinado à construção do parque, o lugar parque que representa o desejo da comunidade. As intercorrências que se interpõem entre o anseio dos moradores e a impossibilidade de o poder público atender a esta demanda, gera, na comunidade, uma diversidade de olhares e significações sobre a situação. Nesse caminho, o grupo pretende que a comunidade possa ressignificar, tanto espaço como o lugar, por meio de um olhar crítico e reflexivo, um olhar espessado pelos significados que surgem da leitura da cena e da abordagem da situação.

Essa proposta dialoga com o conceito de lugar praticado proposto por Michel de Certeau, no que tange a apropriação da cidade pelas pessoas, através do deslocamento pelo espaço urbano, criando textos e construindo seus próprios significados; e estes, subvertem a lógica e a justificativa dos significados oficiais que lhes são atribuídos. Para esse autor, ocorrem fissuras no discurso do poder, através das quais o sujeito pode subverter a ordem e imprimir sua marca por meio da ação (CERTEAU apud CABRAL, 2012, p. 16).

Nesse trajeto com o grupo de trabalho, a proposta foi de apropriação do espaço e sua ressignificação por meio da ação teatral. Na criação desta ação, que constitui a performance de intervenção intitulada Cadê o parque que deveria estar aqui?, tal como colocado acima, utilizamos as inúmeras narrativas elaboradas pelos moradores sobre a situação norteadora do trabalho. As narrativas estão relacionadas ao processo de construção do parque que partiu de uma audiência pública com a comunidade para dar início aos trâmites burocráticos. Nossa percepção, a partir dos relatos sobre as várias instâncias públicas pelas quais o projeto passou e/ou deveria passar para sair do papel, foi da existência de muitos caminhos, alguns percorridos, outros ainda a percorrer. Esses caminhos orientaram e inspiraram a construção da cena.

A ideia foi associada a uma parlenda infantil chamada Cadê o toucinho que estava aqui?, que consiste em uma série de perguntas sobre o paradeiro do sujeito da ação ${ }^{1}$; e nos inspirou a

\footnotetext{
${ }^{1}$ As parlendas são versinhos de temática infantil e rima fácil muito utilizados em brincadeiras de crianças, por adultos para embalar, entreter e distrair crianças, sendo também utilizados como recurso didático para memorização de textos. A versão que utilizamos começa da seguinte forma: "Cadê o toucinho que estava aqui? O gato comeu. Cadê o gato? Foi pro mato. Cadê o mato? O fogo queimou? Cadê o fogo? A água apagou..." Fonte: http://portaldoprofessor.mec.gov.br/fichaTecnicaAula.html?aula=57756. Acesso em: 10 jul. 2019.
} 
criar um coro de moradores e pessoas interessadas ou envolvidas na situação do parque, coro este que vai sendo aumentado por cada personagem surgido ao longo de pequenas trajetórias pelo espaço de atuação.

Foi estabelecida uma sequência desses caminhos, sendo que cada caminho simboliza e leva a um personagem que também simboliza uma instância burocrática a ser percorrida para que o projeto de construção do parque saia do papel. Os caminhos da cena foram elaborados a partir das narrativas construídas pelos moradores sobre a situação (sendo que os relatos foram coletados no próprio grupo e fora dele) e também com um pouco de invenção por parte dos atores.

A sequência se inicia com uma mãe que, ao ser questionada por suas crianças sobre um local para brincar, vai com elas até a Associação dos Moradores saber como está o andamento do processo do parque. A Associação lembra que a audiência pública já tinha sido feita e que foi solicitado o projeto com o arquiteto. A mãe, as crianças e o responsável pela associação vão até o arquiteto e este diz que o projeto já está com o vereador. Todos se encaminham ao vereador, que diz que já passou para o Presidente da Câmara, que diz que o projeto já foi aprovado e que já tinha sido repassado para requerer a Licença Ambiental e por aí vai envolvendo a Marinha, a Construtora responsável pela construção e até o Ministério Público.

No processo de construção dos personagens da cena, trabalhamos com imagens congeladas chamadas de fotografia do personagem. Os participantes pesquisaram gestos característicos de todos os personagens, elegendo, em seguida um gesto registrado nessa fotografia. O grupo selecionou quem faria cada personagem de modo que todos tiveram a oportunidade de fazer, pelo menos, um personagem, sendo que alguns atores fizeram mais de um. Posteriormente, os personagens foram desenvolvidos. Cada ator pesquisou mais características como modo de andar; outros gestos; tom de voz; humores tais como felicidade, cansaço, tristeza; um desejo do personagem e ações que ele poderia realizar.

Para a elaboração da dramaturgia, utilizamos os distintos olhares dos moradores sobre a situação do parque, introduzindo, na cena, os relatos sobre a situação em foco, o envolvimento cotidiano dos moradores com a questão. Assim, diferentes vozes e olhares foram incorporados na cena. No entanto, a proposta dramatúrgica consistiu em elencar aspectos principais do discurso de cada personagem que representa as instâncias públicas nos caminhos do parque. Os atores tiveram liberdade para improvisar a fala a partir do elemento discursivo fundamental de cada personagem. 

Abraão

Itamar Wagner Schiavo Simões

Figura 1 - Construindo a dramaturgia

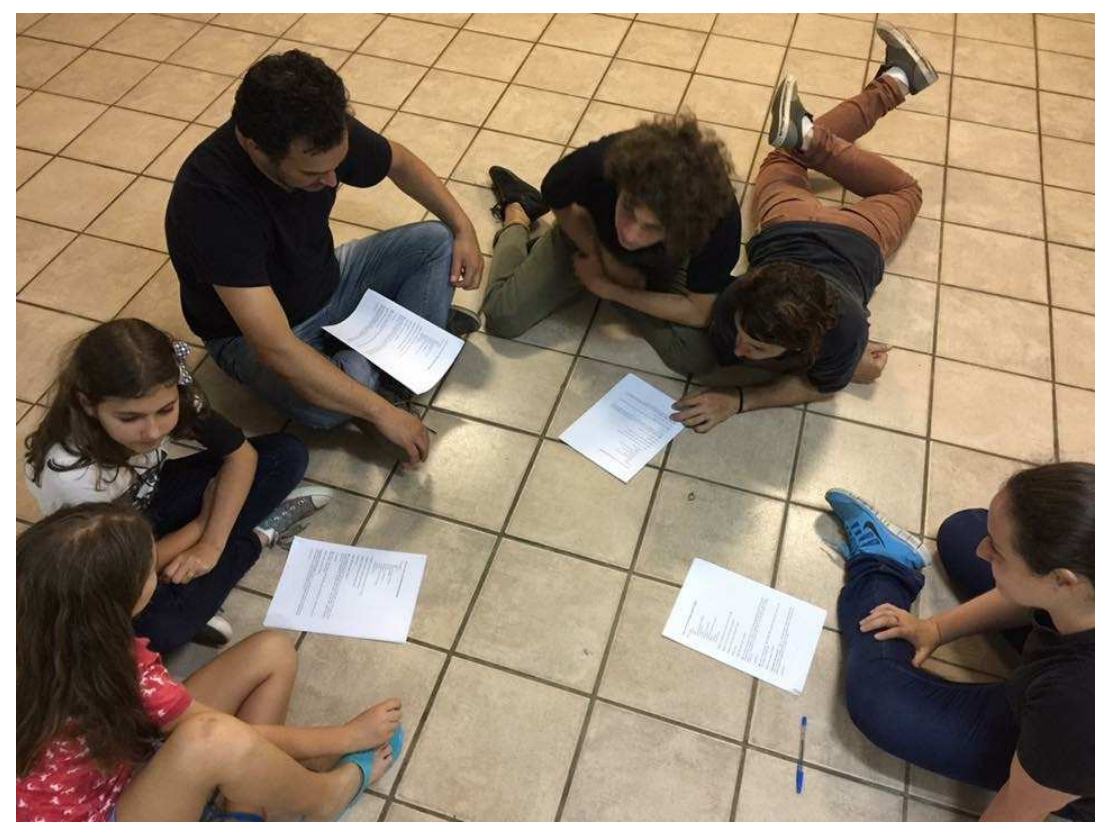

Fonte: do autor (2016).

Construímos a cena de forma que o trabalho de atuação parte da "simples" presença dos atores até a "montagem" de cada personagem em cena. O início se dá com três personagens. Os demais atores estão no espaço como atuantes e cada qual passa a desempenhar seu personagem no momento em que é citado nas falas. Assim que o personagem é citado, o ator veste um item de figurino que caracteriza aquele personagem, vai para o espaço que simboliza a instância burocrática da qual ele é responsável e realiza uma ação característica do tipo social que representa cada instância burocrática. Assim por diante, o coro vai aumentando e percorrendo o espaço de atuação até chegar ao prefeito que diz que tem a solução e convoca a todos a ir com ele. Todos vão caminhando atrás do prefeito, inicialmente entusiasmados. O prefeito não para de dar voltas e o entusiasmo se converte em desânimo diante daquela situação de impasse e de voltas que não se acabam até que a cena se finaliza, com a indagação de todos: Cadê o parque que deveria estar aqui?

Ao chegar a esta configuração cênica, continuamos com o processo de estruturação da performance. Devido ao pouco tempo de trabalho disponível até o fim da prática de ensino, optei pela composição de outras duas cenas a partir de dinâmicas de exploração da linguagem teatral 
Cadê o parque que deveria estar aqui? As trajetórias de uma prática de ensino em Teatro na comunidade do Abraão

Itamar Wagner Schiavo Simões

realizadas na primeira etapa desta caminhada, durante a investigação do onde, quem e o quê. Trata-se dos jogos Máquina Humana e Condução dos cegos.

O primeiro consiste na criação de uma máquina em que cada pessoa representa uma peça desta grande engrenagem. Cada ator se posiciona no espaço realizando um movimento repetitivo e um som respectivo. Os demais vão se posicionando em seguida, completando a engrenagem e criando relações entre as peças. Para a intervenção trabalhamos com máquinas temáticas, uma delas chamada $O$ que se faz no Parque, a outra, Comidas do Parque. A cena deixou claro, os desejos dos moradores quanto ao parque pretendido, como eles gostariam que ele fosse, suas características e peculiaridades.

Figura 2 - Ensaio

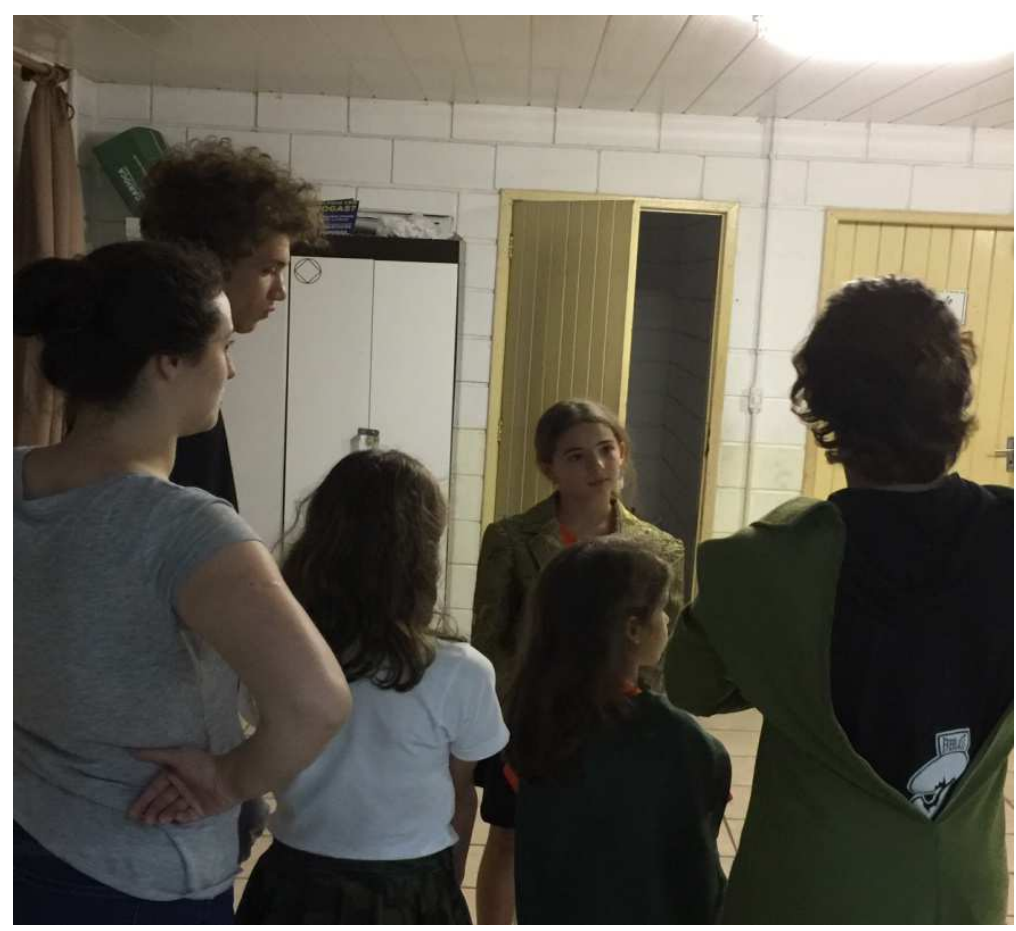

Fonte: do autor (2016).

O segundo jogo é realizado em duplas, nas quais os atores se revezam entre o papel de condutor e cego. O condutor leva o cego ao longo do espaço, variando sua trajetória e o ritmo da caminhada através de um som. O cego, de olhos fechados se deixa conduzir pelo som, com a regra de só caminhar quando ouve o som. Os sons explorados foram aqueles que haveriam no parque idealizado pelos moradores. Os sons produzidos na dinâmica foram o ponto de partida para a 
criação de uma paisagem sonora representativa do parque. As cenas foram ensaiadas, mas deixamos o direcionamento para os atores, para que eles pudessem fazer novas propostas nas apresentações, sob condição de ter relação com o processo criativo e as regras do jogo.

A performance foi estruturada em três quadros. O primeiro formado pela paisagem sonora do parque, o segundo pelas "máquinas humanas" que representavam os desejos dos moradores em relação ao parque, e o terceiro pela cena configurada como o trânsito pelos trâmites de construção do parque.

\section{A CHEGADA, PONTO DE PARTIDA PARA UMA NOVA TRAJETÓRIA}

Nesta experiência com os moradores, a contribuição individual de cada um em busca de um diálogo com o coletivo (a comunidade), foi o fulcro do processo criativo de transformação do espaço cotidiano em um espaço ficcional potente de ressignificações. As tensões entre espaço e lugar a serem provocadas pela intervenção, possuem o potencial de atrair diferentes olhares dos moradores espectadores causando impacto estético e social. Segundo Cabral (2012), uma encenação teatral que envolva um grupo heterogêneo de participantes na criação e ressignificação de histórias e do lugar em que vive, requer que seja considerado o sentido de experiência no nível individual e coletivo. A autora (2012, p. 23) pontua que o impacto pode ser observado, principalmente "em decorrência do deslocamento do espaço (uso não usual), do encontro com o outro, ou do inesperado da abordagem ou da situação introduzida (ações ou evidência de uma agenda oculta relacionada com a história e o lugar)". Nossa proposta de trabalho caminha na direção dessa ideia, pelo próprio uso extracotidiano do espaço, pelo deslocamento proposto entre espaço e lugar praticado e pela ação que busca desvelar a agenda oculta na forma das narrativas elaboradas pelos moradores sobre a situação do parque.

Uma das primeiras considerações para a elaboração desse projeto, foi o deslocamento do espaço teatral para o espaço público, buscando contemplar os interesses dos moradores da comunidade, enfocando seus questionamentos artísticos e estéticos. O espaço teatral se desloca para o espaço público e o espectador para o acontecimento teatral. Os questionamentos surgidos no espaço transformado, ocorrem por meio da relação entre imaginário e real, fictício e real e entre espaço prático e espaço figural. Assim, os questionamentos da cena e os deslocamentos entre 
Cadê o parque que deveria estar aqui? As trajetórias de uma prática de ensino em Teatro na comunidade do Abraão

Itamar Wagner Schiavo Simões

imaginário, realidade, fiç̧ão, ação e figuração são potencializados por serem propostos para o público no espaço onde o parque deveria estar construído.

Pode-se dizer que além do deslocamento do imaginário teatral no teatro realizado nos espaços públicos, também acontece o deslocamento do espaço teatral, onde o real e o imaginário confundem-se, a arte permeia a vida e o cotidiano, traçando linhas de fuga e gerando realidades outras (MUNIZ, 2011, p. 81).

O trabalho foi compartilhado em uma Mostra de Teatro Comunitário na Udesc, que funcionou como um ensaio aberto. Depois dessa apresentação, foram realizados dois outros ensaios para alguns retoques e acabamentos necessários após o compartilhamento do processo. A intervenção na comunidade aconteceu nos dias 17, 18 e 19 de dezembro de 2016. Depois de cada apresentação foi realizada uma roda de conversa com os espectadores.

Figura 3 - Compartilhamento do processo na Udesc

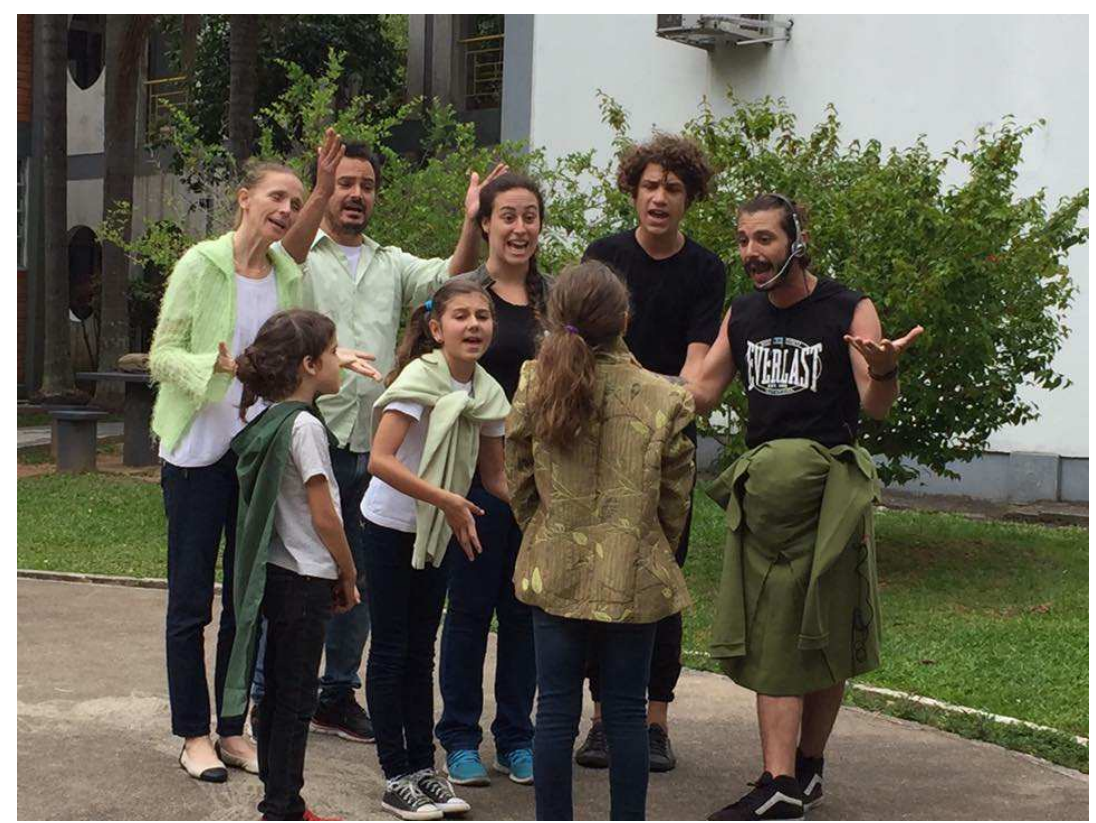

Fonte: do autor (2016). 

Abraão

Itamar Wagner Schiavo Simões

Figura 4 - Intervenção na Comunidade

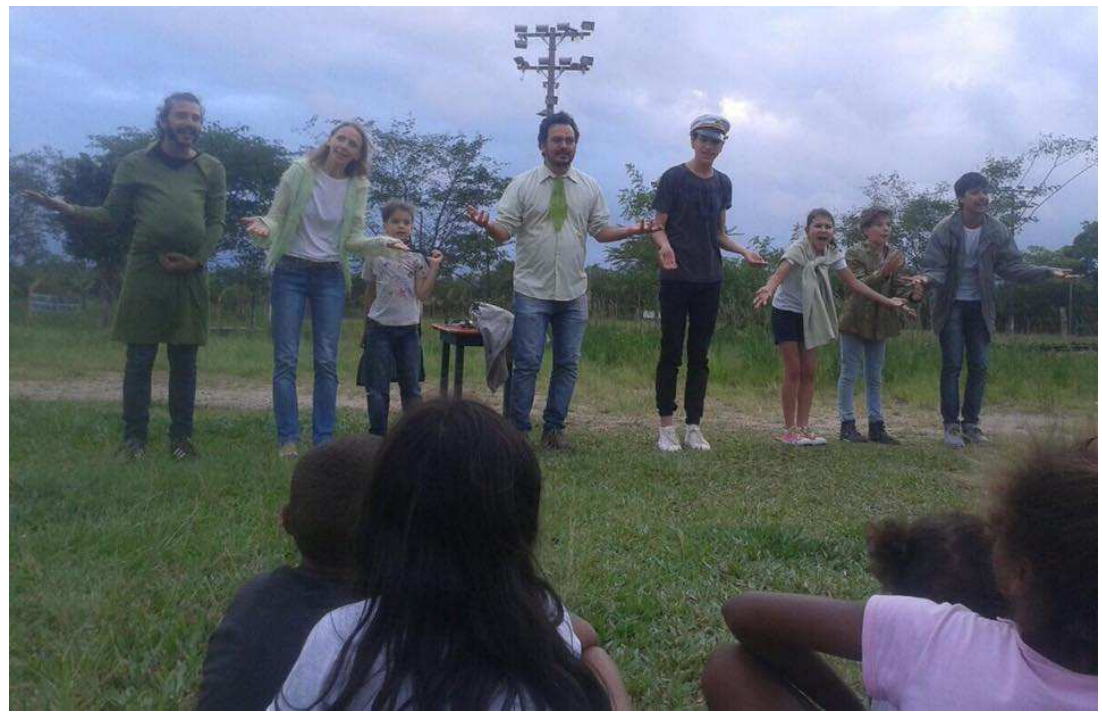

Fonte: do autor (2016).

\section{CONSIDERAÇÕES FINAIS: QUAL É A PRÓXIMA CAMINHADA?}

Essa prática abriu caminhos de diálogo entre o grupo e os moradores sobre a questão do parque. Os moradores puderam atribuir outros significados a respeito da situação enfocada, estimulando seu debate, inclusive pelo fato de que eles tinham outras informações sobre as questões que envolviam a construção do parque. Isso ficou evidente nas rodas de conversas. Surgiram outras versões e olhares, trilhas e desvios que se inseriram sobre as trajetórias propostas pelo grupo. Nesse sentido, a mobilidade de significação emergida da interação entre quem vê e os que fazem e do confronto entre o que se vê e o que se sabe, direciona para um rito social com privilégio, na apreciação estética, na produção de subjetividades.

A efetivação do lugar praticado ocorre não apenas pela realização da intervenção cênica no espaço público, mas pelo envolvimento gerado entre os espectadores-moradores com a abordagem de questões relativas ao lugar que se vive, contribuindo para o engajamento com a causa da construção do parque, para a sensação de pertencimento e para a percepção da importância do cuidado com o espaço público.

As rodas de conversas e outros olhares sobrepostos sobre a situação provocaram o grupo a ampliar esta narrativa cênica incorporando novos elementos advindos do processo de fruição da cena. O trabalho também contribuiu, como esperado, para divulgação do grupo e dos encontros teatrais na comunidade; muitos não sabiam da existência do grupo e da atividade teatral contínua 
Cadê o parque que deveria estar aqui? As trajetórias de uma prática de ensino em Teatro na comunidade do Abraão

Itamar Wagner Schiavo Simões

no bairro. O grupo também foi bastante provocado e motivado a dar continuidade às experimentações cênicas que tratem de temas do cotidiano da comunidade.

\section{REFERÊNCIAS}

CABRAL, Beatriz Ângela Vieira. Teatro em trânsito: a pedagogia das interações no espaço da cidade. São Paulo: Hucitec, 2012.

DESGRANGES, Flávio. A pedagogia do teatro: provocação e dialogismo. São Paulo: Hucitec, 2006.

MUNIZ, Z. O espaço público como espaço cênico: possibilidade de acontecimento e experiência. In: CARREIRA, André (org.) Teatralidade e Cidade. Florianópolis: UDESC, 2011. (Cadernos do Urdimento, 1).

OLIVEIRA, Cleber Rodrigo Braga de. Uma cartografia de intervenções urbanas artísticas: sul da Espanha e da América do Sul. 2013. Dissertação (Mestrado em Teatro) - Centro de Artes, Universidade do Estado de Santa Catarina, Florianópolis, 2013.

PEREIRA, Cássia Correa. Arte e a condição de urbanidade. In: COLÓQUIO INTERNACIONAL DE HISTÓRIA DA CIDADE, 1., 2015, Porto Alegre. Anais [...]. Porto Alegre: UFRGS, 2015. p. 162-178. Disponível em: http://www.ufrgs.br/gthistoriaculturalrs/12CDCassiaCorreaPereira.pdf. Acesso em: 10 jul. 2019.

SPOLIN, Viola. Jogos teatrais: o fichário de Viola Spolin. São Paulo: Perspectiva, 2001. 